\title{
Intramedullary splinting of femoral shaft fractures in children with flexible nails: early results
}

\author{
Arun Kumar Kaliya Perumal' ${ }^{1}$, MS, Kanthimathi Balasubramanian², DNB
}

INTRODUCTION Indications for flexible intramedullary nailing, as well as advancements in this technique, have evolved considerably with time and individual experience. We implemented and studied a simplified version of the technique. Functional outcome, osseous union and related issues are discussed.

METHODS A total of 15 patients aged 5-15 years with diaphyseal femur fracture were selected for the study. The patients' fractures were stabilised with flexible intramedullary nails through lateral entry alone. After a minimum follow-up period of six months, the outcomes were analysed.

RESULTS The mean patient age was 8.7 years, and patients were followed up for a mean duration of 12 months. Radiological union was achieved within a mean duration of 7.5 weeks. The outcomes were excellent in most of the cases.

CONCLUSION Adequate fixation was achieved through the use of flexible nails as intramedullary splints. The results were comparable to that of the original technique. Further study is obligatory.

Keywords: elastic stable intramedullary nailing, flexible intramedullary nailing, paediatric femur fracture

\section{INTRODUCTION}

Elastic stable intramedullary nailing (ESIN) is a simple technique that is minimally invasive. It has been shown to produce promising results, and to date, remains the preferred treatment method for selected paediatric femoral shaft fractures. ${ }^{(1-3)}$ ESIN minimises the duration of hospital stay and offers a faster recovery time for the patient. The principle of counteracting the trifocal buttressing effect in the medullary cavity requires two nails to be inserted through dual entry windows made on either side of the femur - one laterally and one medially. ${ }^{(2)}$ The nails are contoured to bring about an equal counter buttressing effect in the medullary cavity.

Deviating from the original technique, elastic nails are inserted through lateral entry alone to adequately fill the medullary cavity and achieve a form of rigid intramedullary fixation that differs from the Nancy nailing method. ${ }^{(1,2)} \mathrm{A}$ sufficiently wide bony window that allows the snug passage of at least two nails needs to be made in the lateral cortex so that stability is not compromised. A minimum of $80 \%$ filling of the medullary cavity is considered reasonable. In this study, we aimed to analyse the technical issues and outcome of treating selective paediatric femoral fractures with this method. The advantages and disadvantages are discussed.

\section{METHODS}

A total of 15 paediatric patients who presented to our institution with diaphyseal fracture of the femur were selected for the study. Their fractures were stabilised with flexible intramedullary nails through lateral entry alone. We observed the adequacy of nails inserted through lateral entry alone to stabilise the fractured femur in the patients. The inclusion criteria were: (a) femoral shaft fractures; (b) age 5-15 years; and (c) simple closed diaphyseal fractures. The exclusion criteria were: (a) proximal and distal fractures; (b) compound and segmental fractures; and (c) length-unstable fracture patterns. The final sample consisted of 11 male and 4 female patients, with a mean age of 8.7 years. Of the 15 patients, 8 had fractures of the right femur and 7 had fractures of the left femur. The average body mass index (BMI) of the patients was 21.1 (range 18.2-24.2) $\mathrm{kg} / \mathrm{m}^{2}$. All were in the normal weight category, except for one patient who was underweight (BMI $18.2 \mathrm{~kg} / \mathrm{m}^{2}$ ).

All 15 patients were received in the emergency department, where their fractures were initially stabilised. None of the patients had associated injuries or other comorbidities. After thorough clinical assessment, the fractures were temporarily immobilised. Standard anteroposterior and lateral radiographs were taken, demonstrating fractures of the middle third (Fig. 1) in eight patients, proximal and middle third junction fractures in six patients, and middle and distal third junction fracture in one patient. The fracture patterns were classified as either transverse or oblique. Canal diameter was also measured from preoperative radiographs. Nails were selected according to Flynn et al's formula, which gives two equally sized nails that

${ }^{1}$ Department of Orthopaedics, Melmaruvathur Adhiparasakthi Institute of Medical Sciences and Research, ${ }^{2}$ Department of Orthopaedics, Rajah Muthiah Medical College and Hospital, Tamil Nadu, India

Correspondence: Dr Arun Kumar Kaliya Perumal, Professor and Unit Chief, Sakthi Medicare Center, 112 Bazaar Street, Chidambaram, Tamil Nadu 608002, India. dr.arunkumar.orth@gmail.com 


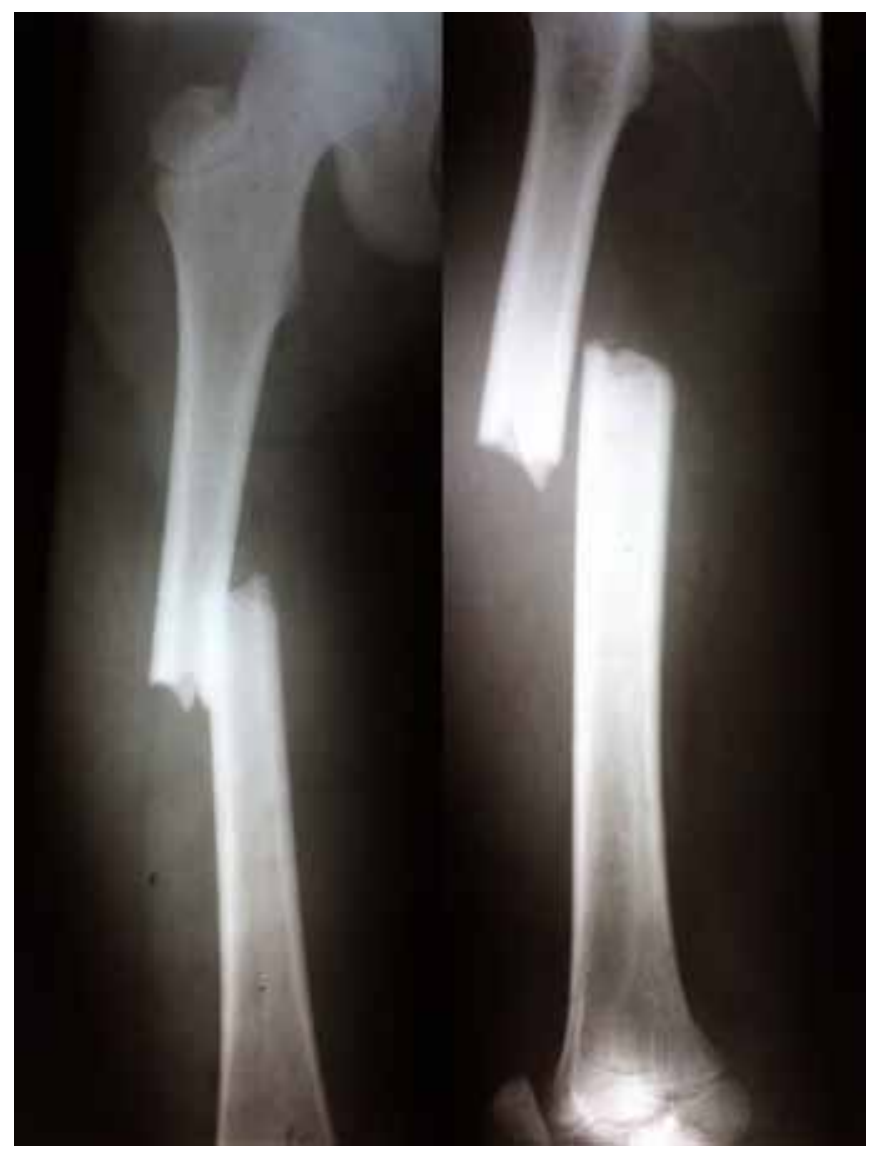

Fig. 1 Preoperative anteroposterior and Iateral radiographs show a femoral shaft fracture of the middle third in a patient.

fill $80 \%$ of the medullary cavity: ${ }^{(4)}$ diameter of nail $=$ width of the narrowest point of the medullary canal on anteroposterior and lateral view $\times 0.4 \mathrm{~mm}$.

All patients underwent retrograde nailing within three days of trauma. Under anaesthesia, they were placed in a lateral position with the affected side facing upwards. The opposite hip and knee were flexed to about $90^{\circ}$. A pillow was kept under the affected thigh to elevate its plane from the other limb. The image intensifier was positioned accordingly to ensure no overlapping of bones (Figs. 2a \& b). A short incision was made $2.5 \mathrm{~cm}$ proximal to the physis through which the lateral cortex was approached. An entry window was made in the lateral cortex using a curved awl. Appropriately sized titanium elastic nails were selected. Since counteracting trifocal buttressing was not expected, the nails were not pre-bent.

The first nail was introduced and advanced into the distal fragment up to the fracture site. Following manual closed reduction, the nail was further advanced into the proximal fragment up to the desired proximal placement under the guidance of an image intensifier. The second nail was inserted through the same entry window. After placement of the nail, image intensifier guidance was sought to confirm its position. Most of the cases showed intramedullary placement of the second nail at first attempt. $80 \%$ filling of the medullary cavity was considered mandatory. In one case, a third nail was inserted so as to adequately fill the medullary cavity. In two
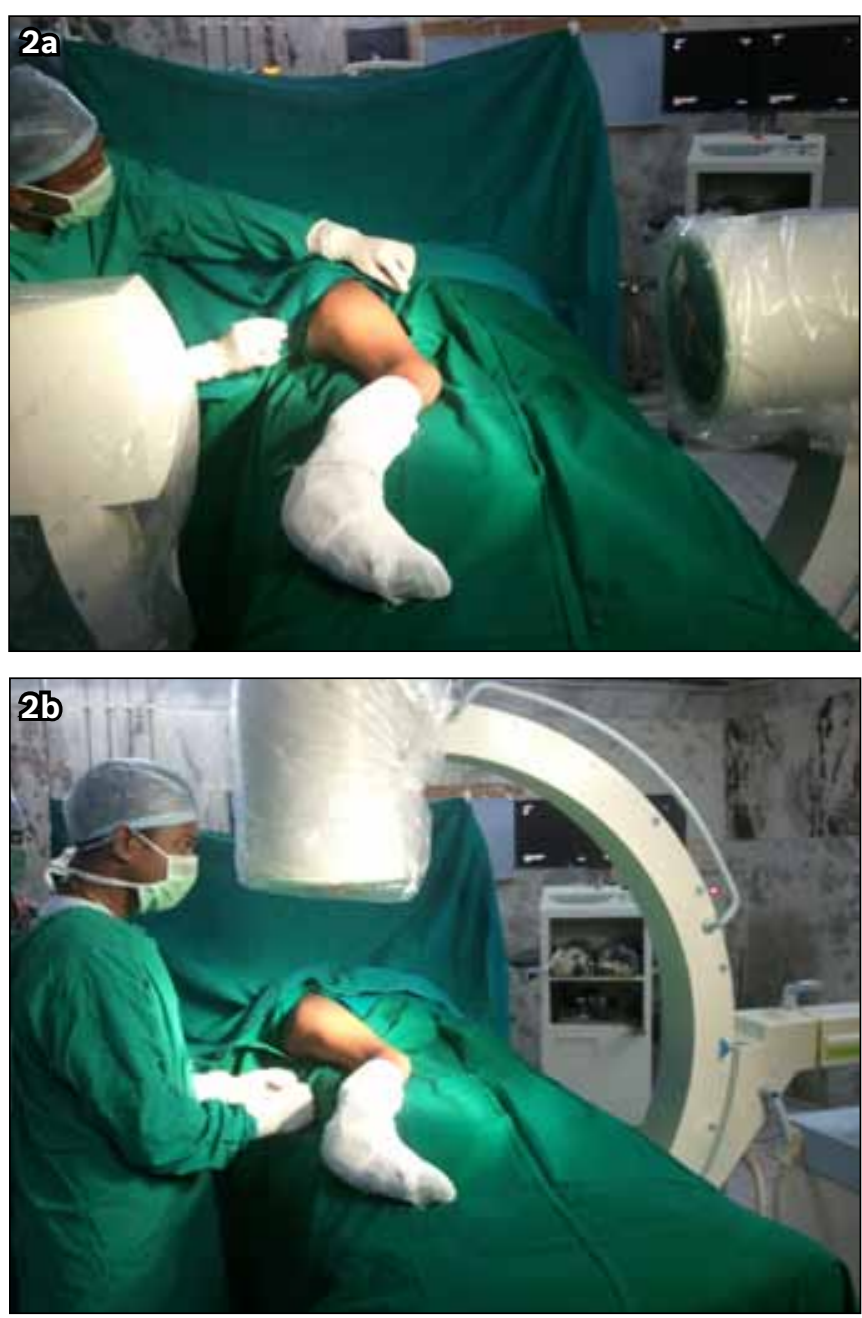

Fig. 2 Intraoperative photographs show the positions of the patient and the C-arm for the (a) anteroposterior and (b) lateral views.

earlier cases, the nail tips were bent after placement of the nails; this was not repeated in the rest of the patients. The mean duration of surgery was 37 mins. All reductions were satisfactory intraoperatively. Given the significant remodelling potential of the immature skeleton, anatomical reduction was not the intraoperative goal. Negligible offset and angulations were left alone.

None of the patients required postoperative immobilisation. By the middle of the first week, the hip and knee were mobilised; this was well tolerated by all patients. Postoperative radiographs taken revealed satisfactory reduction. Prophylactic oral antibiotics were administered for up to one week after surgery, and there were no cases of infection. Prior to discharge, patients were clinically assessed for pain at the entry site, range of motion, rotational alignment and discrepancies in limb length. They were also advised on quadriceps strengthening and discharged after suture removal. Periodic reviews were conducted every two weeks to assess functional outcome and osseous union. Radiographs were also taken at regular intervals to screen for callus.

The results were tabulated according to Flynn and Schwend's scoring criteria. ${ }^{(5)}$ Based on this criteria, 'excellent 


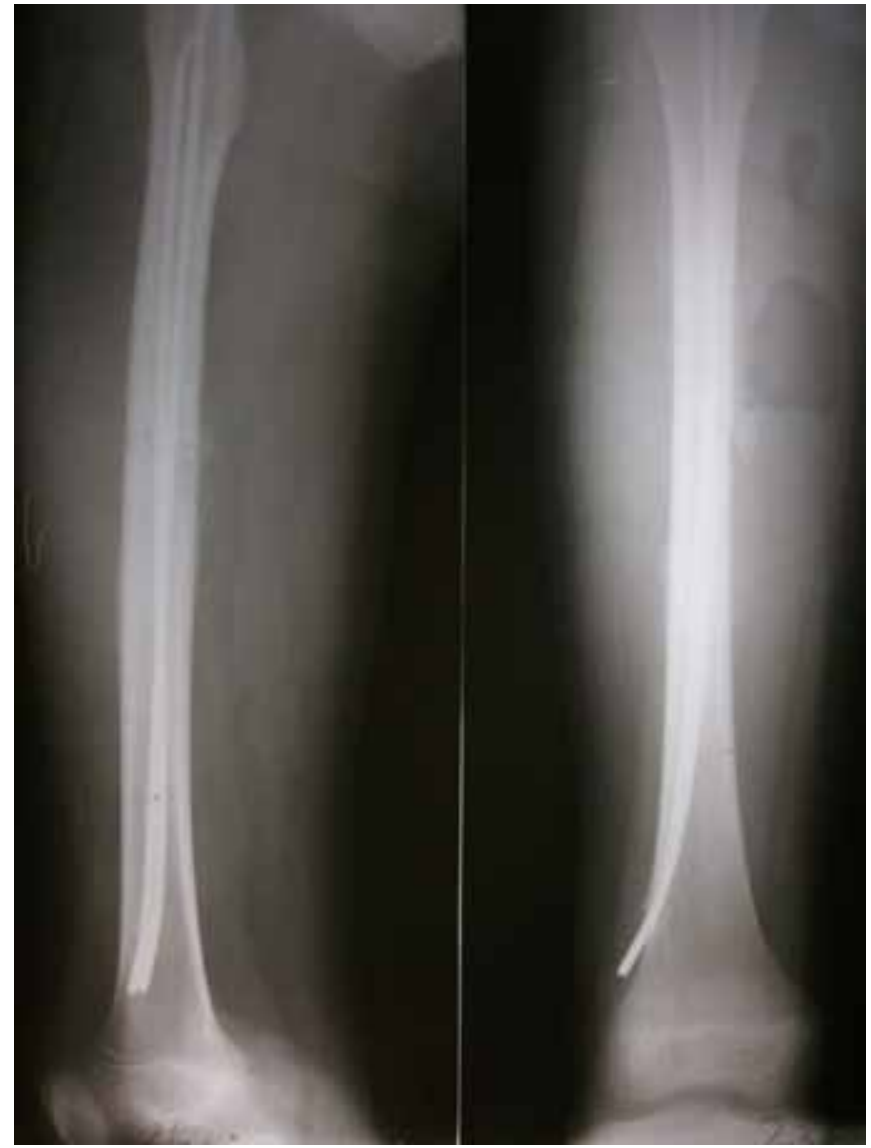

Fig. 3 Postoperative anteroposterior and lateral radiographs show satisfactory reduction of the fracture in a patient.

results' are defined as: (a) limb length discrepancy (LLD) $<1 \mathrm{~cm}$; (b) angulation < 5 ; (c) absence of pain; and (d) no other complications. Also, 'satisfactory results' are defined as: (a) LLD 1-2 cm; (b) angulation $5^{\circ}-10^{\circ}$; (c) absence of pain; and (d) mild complications; and 'poor results' are defined as: (a) LLD > $2 \mathrm{~cm}$; (b) angulation $>10^{\circ}$; (c) presence of pain; and (d) major complications.

This study was reviewed by the institution's ethics committee and performed in accordance with the ethical standards laid down in the 1964 Declaration of Helsinki.

\section{RESULTS}

Postoperative radiographs revealed satisfactory reduction in all patients (Fig. 3). By the end of the first postoperative week, full range of motion of the hip and up to $90^{\circ}$ of flexion at the knee were noted in the patients. Further flexion of the knee caused entry site pain, which was more intense in patients whose nail tips were bent. By the end of the second week, the range of motion at the knee significantly improved up to $120^{\circ}$. LLD of $1 \mathrm{~cm}$, measured from the anterior superior iliac spine to the medial malleolus on the affected side and compared with the normal limb, was noted in two patients. Rotational malalignment was checked by comparing the internal and external rotations of both limbs. None of the patients showed any anomaly.

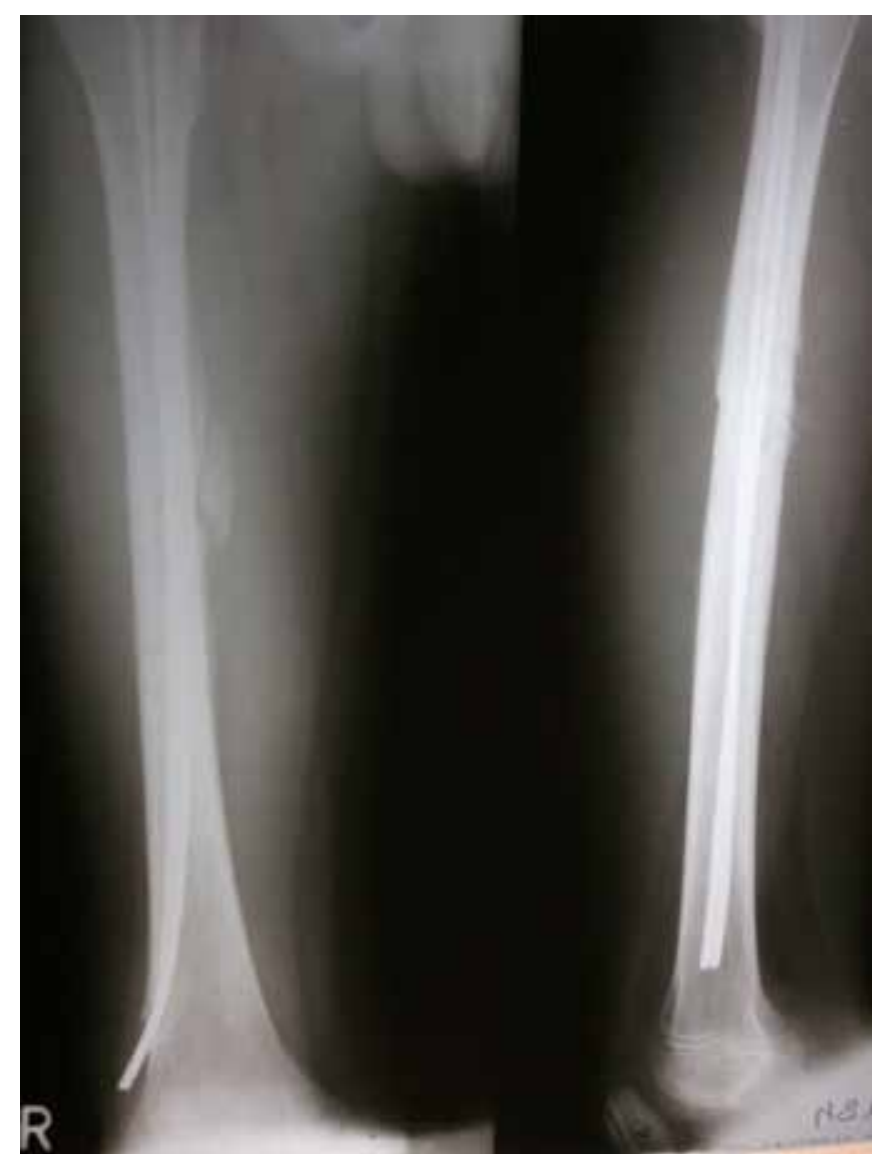

Fig. 4 Postoperative anteroposterior and lateral radiographs show callus around the fracture.

At four weeks after surgery, radiographs of the patients revealed the presence of callus around the fracture (Fig. 4). Of the 15 patients, 14 regained full range of motion of both the hip and knee. One patient had entry site pain and difficulty in extreme flexion of the knee, likely due to the bent nail tip. LLDs that were observed earlier persisted. All the patients had full power of the quadriceps. There was no rotational malalignment or any other late onset complications in any of the patients. Quadriceps strengthening was continued and weight bearing was restricted until radiological union was seen.

By six weeks, all the patients had full range of motion and no associated pain. Among those who previously had LLDs, one had further shortening of up to $1.5 \mathrm{~cm}$ and that of the other patient remained at $1 \mathrm{~cm}$. No angulations at the fracture site were noticed during follow-up. Union was achieved within a mean duration of 7.5 weeks (range 7-9 weeks). Upon union of the fractures, all the patients were allowed to bear weight with assistance and under supervision, and this was well tolerated by the patients. Those who continued to have shortening were prescribed raised-heel footwear.

By postoperative week 12, all 15 patients had returned to pre-injury status. Further follow-up revealed one patient with a limb lengthening of $<1 \mathrm{~cm}$. One patient had another episode of trauma six months after surgery and sustained refracture to the 
Table I. Demographic and clinical data of the series $(n=15)$.

\begin{tabular}{|c|c|c|c|c|c|c|c|c|c|}
\hline $\begin{array}{l}\text { Patient } \\
\text { no. }\end{array}$ & $\begin{array}{l}\text { Age (yrs); } \\
\text { gender }\end{array}$ & Side & Site & Pattern & $\begin{array}{l}\text { No. of } \\
\text { nails }\end{array}$ & $\begin{array}{l}\text { Union } \\
\text { (wks) }\end{array}$ & $\begin{array}{l}\text { Normal activity } \\
\text { (wks) }\end{array}$ & $\begin{array}{l}\text { LLD } \\
(\mathrm{cm})\end{array}$ & Result \\
\hline 1 & 5; Male & Left & PM & Oblique & 2 & 7 & 10 & - & Excellent \\
\hline 3 & 6; Female & Right & M & Oblique & 2 & 7 & 10 & $\begin{array}{l}0.5 \\
\text { Lengthening }\end{array}$ & Excellent \\
\hline 4 & 6; Male & Right & M & Transverse & 2 & 7 & 10 & - & Excellent \\
\hline 5 & 7; Male & Left & M & Oblique & 2 & 8 & 10 & $\begin{array}{l}1.0 \\
\text { Shortening }\end{array}$ & Satisfactory \\
\hline 6 & 8; Female & Right & PM & Transverse & 2 & 7 & 10 & - & Excellent \\
\hline 7 & 8; Male & Left & M & Oblique & 2 & 9 & 11 & - & Excellent \\
\hline 8 & 8; Male & Right & PM & Transverse & 2 & 7 & 10 & - & Excellent \\
\hline 9 & 9; Male & Right & PM & Transverse & 2 & 7 & 10 & - & Excellent \\
\hline 11 & 9; Female & Left & M & Transverse & 2 & 7 & 10 & $\begin{array}{l}1.5 \\
\text { Shortening }\end{array}$ & Satisfactory \\
\hline 12 & 11; Male & Right & PM & Oblique & 3 & 8 & 11 & - & Excellent \\
\hline 13 & 12; Male & Right & M & Oblique & 2 & 8 & 11 & - & Excellent \\
\hline 14 & 13; Male & Left & MD & Transverse & 2 & 8 & 12 & - & Excellent \\
\hline 15 & 15; Male & Left & $M$ & Oblique & 2 & 8 & 11 & - & Excellent \\
\hline
\end{tabular}

PM: proximal and middle third junction; M: middle third; MD: middle and distal third junction; LLD: limb length discrepancy

same femur with the elastic nails in situ. This patient was conservatively managed. All patients were followed up for a minimum of six months. The mean duration of follow-up was 12 months.

At final follow-up, two patients had a significant shortening of $1.5 \mathrm{~cm}$ and $1.0 \mathrm{~cm}$, respectively. Another patient had an insignificant lengthening of $0.5 \mathrm{~cm}$. Apart from the refracture that occurred in one of the patients, no other complications were noted. Although two nails had been inserted through the same bone window, there were no reported cases of nail backout, even at final follow-up. According to Flynn and Schwend's scoring criteria, ${ }^{(5)} 13$ out of 15 (86.7\%) of our patients obtained excellent results, and 2 (13.3\%) had satisfactory results. None of our patients obtained poor results (Table I).

\section{DISCUSSION}

Elastic stable intramedullary nailing was first described by surgeons in Nancy, France. ${ }^{(6)}$ This technique is said to be ideal for the treatment of a transverse or short, oblique diaphyseal fracture with or without minimal comminution in a long bone. ${ }^{(3)}$ The principle behind the technique involves bringing a trifocal buttressing effect in the medullary cavity, which is counteracted by the buttressing of the other nail. ${ }^{(2,3)}$ This demands dual entry - one medially and one laterally. In recent years, indications for flexible intramedullary nailing, as well as advancements in this technique, have evolved considerably with time and individual experience.

In our institution, we utilised the Nancy nailing technique until we encountered a patient with superficial abrasions, which prevented us from making a medial incision.
In that instance, the fracture was nailed through the lateral entry alone. As the results of this method did not show any deviation from those of the previous method in terms of postoperative rehabilitation, radiological union or weight bearing, we were prompted to utilise a similar operative technique as well as study whether lateral entry alone is sufficient to splint selective paediatric femur fractures.

In our series, this method was used only for stable fracture patterns, as described in the Nancy studies. ${ }^{(2)}$ It was considerably easier to work with patients who were placed in a lateral position. Lateral entry nails provided enough stability so that there was no incidence of loss of reduction intra- and postoperatively. Nails of a similar size were preferred for most of our cases, although this was not necessary, as the nails were merely being used as intramedullary splints. The number of nails can also be varied accordingly to give additional stability, as was done in one of our cases where the medullary cavity was packed with three nails. However, care has to be taken to not make a very wide entry window, so as to prevent subsequent nail backout. Except for the shortening that occurred in two patients, no incident of collapse or angulation was noted in our series.

In terms of osseous union and return to normal activity, our results were comparable to those of other studies. ${ }^{(7-12)}$ Excellent results were evidenced in early mobilisation, weight bearing and return to normal activities among our patients. The duration of surgery was also relatively short and the patients were comfortable with minimal scarring only on the lateral aspect. Biological fixation was achieved with the benefit of lateral entry alone, along with ease of implant removal. 
Although the ultimate goal of restoring the patient to normal activity was reached within the desired time and with only a single scar, this simplified technique needs to be further studied. Currently, long-term results are not available. This study has some methodological shortcomings, including a small sample size and the absence of a control group. Further prospective randomised studies are necessary in order to assess the exact role and feasibility of this method in the management of selective paediatric femur fractures.

\section{REFERENCES}

1. Khazzam M, Tassone C, Liu XC, et al. Use of flexible intramedullary nail fixation in treating femur fractures in children. Am J Orthop (Belle Mead NJ) 2009; 38:E49-55.

2. Metaizeau JP. Stable elastic intramedullary nailing for fractures of the femur in children. J Bone Joint Surg Br 2004; 86:954-7.

3. Barry M, Paterson JM. Flexible intramedullary nails for fractures in children. J Bone Joint Surg Br 2004; 86:947-53.

4. Flynn JM, Skaggs DL, Sponseller PD, et al. The operative management of pediatric fractures of the lower extremity. J Bone Joint Surg Am 2002; 84:2288-300

5. Flynn JM, Schwend RM. Management of pediatric femoral shaft fractures. J Am Acad Orthop Surg 2004; 12:347-59.

6. Ligier JN, Metaizeau JP, Prévot J, Lascombes P. Elastic stable intramedullary nailing of femoral shaft fractures in children. J Bone Joint Surg Br 1988; 70:74-7.

7. Singh R, Sharma SC, Magu NK, Singla A. Titanium elastic nailing in pediatric femoral diaphyseal fractures. Indian J Orthop 2006; 40:29-34.

8. Saikia K, Bhuyan S, Bhattacharya T, Saikia S. Titanium elastic nailing in femoral diaphyseal fractures of children in 6-16 years of age. Indian J Orthop 2007; 41:381-5.

9. El-Adl G, Mostafa MF, Khalil MA, Enan A. Titanium elastic nail fixation for paediatric femoral and tibial fractures. Acta Orthop Belg 2009; 75:512-20.

10. Heybeli M, Muratli HH, Celebi L, Gülçek S, Biçimoğlu A. [The results of intramedullary fixation with titanium elastic nails in children with femoral fractures]. Acta Orthop Traumatol Turc 2004; 38:178-87. Turkish.

11. Mortier D, De Ridder K. Flexible intramedullary nailing in the treatment of diaphyseal fractures of the femur in preschool children. Acta Orthop Belg 2008; 74:190-4.

12. Flynn JM, Hresko T, Reynolds RA, et al. Titanium elastic nails for pediatric femur fractures: a multicenter study of early results with analysis of complications. J Pediatr Orthop 2001; 21:4-8.

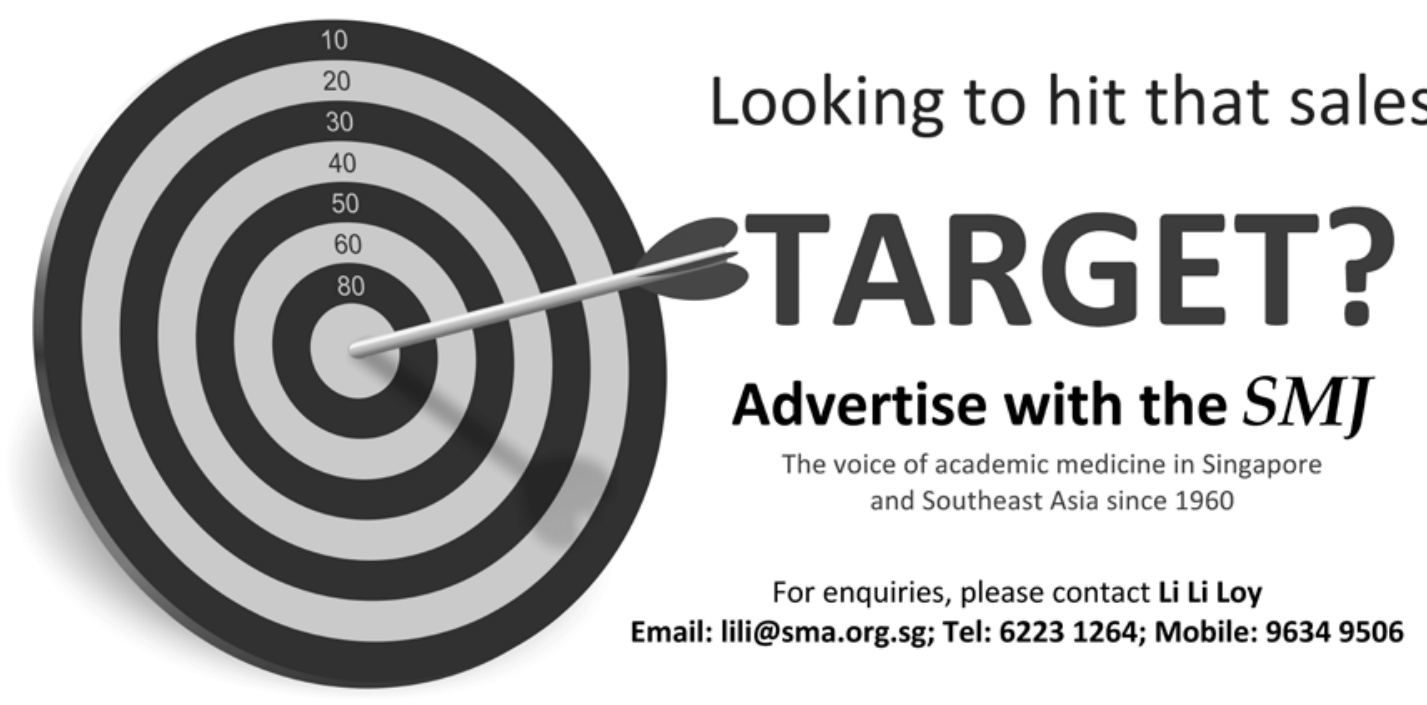

